\title{
Obituary Prof. Dr. Dietrich Harder (11 February 1930-10 February 2019)
}

\author{
Rüdiger Greinert ${ }^{1} \cdot$ Michael Hausmann ${ }^{2}$
}

Received: 3 April 2019 / Accepted: 4 April 2019 / Published online: 9 April 2019

c) Springer-Verlag GmbH Germany, part of Springer Nature 2019

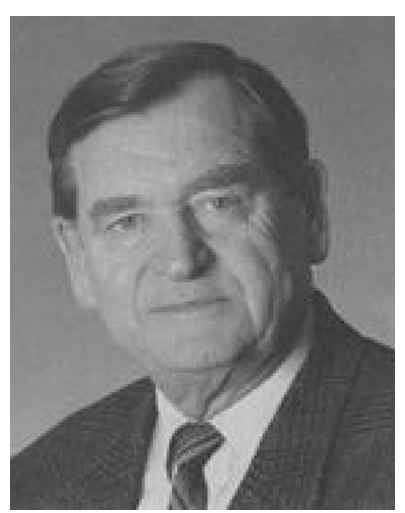

The "Deutsche Gesellschaft für Biologische Strahlenforschung" (DeGBS; German Society for Biological Radiation Research) is grieving for its founder and honorary member Prof. Dr. Dietrich Harder, who has unexpectedly died. From 1974 to 1999, he was full professor for Medical Physics and Biophysics at the Medical Faculty of the University of Göttingen and director of the Institute of Medical Physics and Biophysics at the University Medical Centre, Göttingen, Germany.

Prof. Harder significantly contributed to radiation research-understanding radiation interaction on the cellular level, especially mechanisms of chromosome aberration induction for understanding and measurements of relative biological effectiveness (RBE). After his retirement, he continued his work, especially in the context of radiation protection with a focus on the balance between radiation risk and in curative effects of Radon. After the German unification, his activities significantly promoted the reconstruction of the Radon therapeutic baths in Bad Schlema and the local research of Radon effects and the history of the city. Besides his scientific contributions to radiation research, Prof. Harder was appointed to many national and international committees of radiation protection and safety. Prof Harder was founder and first editor of the "Zeitschrift für Medizinische Physik". His initiative and his continuous engagement for radiation research and promotion of young scientists significantly contributed to the foundation of "Gesellschaft für Biologische Strahlenforschung" (GBS, today DeGBS) in 1996. He was president of GBS from 1996 to 1998. For his merits, he was awarded with many prizes as, for instance, the "Hermann-Holthusen-Ring" of the German Röntgen Society, "Timoféeff-Ressovsky-Medal" of the Russian Academy of Medical Sciences, or the "Ulrich-Hagen-Award" of the GBS in 2005. For his meritoriousness in radiation protection, he was awarded with the Federal Cross of Merits by the President of the Federal Republic of Germany.

On behalf of the council of DeGBS,

Rüdiger Greinert and Michael Hausmann (Senior President)

\section{Compliance with ethical standards}

Conflict of interest The authors declare that they have no conflict of interest.

Publisher's Note Springer Nature remains neutral with regard to jurisdictional claims in published maps and institutional affiliations.

Michael Hausmann

hausmann@kip.uni-heidelberg.de

1 Skin Cancer Center Buxtehude, Elbekliniken Stade/ Buxtehude, Buxtehude, Germany

2 Kirchhoff-Institut für Physik, Ruprecht-Karls-Universität, Heidelberg, Germany 